\title{
Congenital tracheoesophageal, umbilical, vascular and meningeal fistulas
}

\begin{abstract}
Tracheoesophageal fistula and esophageal atresia are rare congenital abnormalities which represent two components of VACTERL association of anomalies. They are frequently associated with laryngeal cleft. Congenital umbilical fistulas result from failure of obliteration of the fetal vitellointestinal duct or urachus. Vitellointestinal duct abnormalities are rare and they include Meckel's diverticulum, vitelline cyst and vitellointestinal fistula. Urachal anomalies are very rare, and they include diverticula, cysts, sinuses and fistulas. Ultrasonography and fistulography are helpful investigations for the diagnosis of urachal fistulas; the fistula is surgically excised together with the adjoining apex of the urinary bladder. Congenital prepubic sinuses and urethroperineal fistulas are other rare anomalies. Congenital coronary artery fistulas may be also discovered between the coronary arteries and the four cardiac chambers or the great vessels of the heart. Coronary arteriovenous fistulas and absent ductus venosus with abnormal venous circulation could occur as rare congenital anomalies. Other rare congenital arteriovenous fistulas could exist in the thorax, abdomen, pelvis, and cranial and spinal meninges.
\end{abstract}

Keywords: congenital, fistulas, trachea-esophageal, vitellointestinal, urachal, arteriovenous, meningeal
Volume 5 Issue 5 - 2018

\author{
Heshmat SW Haroun \\ Professor of Anatomy and Embryology, Faculty of Medicine, \\ Cairo University, Egypt
}

\author{
Correspondence: Heshmat SW Haroun, Professor of \\ Anatomy and Embryology, Faculty of Medicine, Cairo University, \\ Egypt, \\ Email heshmatsabat@gmail.com, \\ heshmat.harous@kasralainy.edu.eg.com
}

Received: October 01, 2018 | Published: October 12, 2018
Abbreviations: AVF, arteriovenous fistula; CPS, congenital prepubic sinus; CUFs, congenital umbilical fistulas; EA, esophageal atresia; GERD, gastroesophageal reflux disease; HUC, hernia of umbilical cord; IVC, inferior vena cava; OMD, omphalomesenteric duct; TEF, tracheoesophageal fistula; VID, vitellointestinal duct

\section{Introduction}

Fistula is a pathological tract connecting two internal cavities or an internal cavity with body surface. In addition to congenital fistulas of the head and neck which we have previously reviewed ${ }^{1}$ congenital tracheoesophageal, umbilical, arteriovenous and nervous fistulas are described here.

\section{Tracheoesophageal fistula and VACTERL association}

Esophageal atresia (EA) is a rare congenital anomaly (1:25004500 live births) which is most frequently associated with tracheoesophageal fistula (TEF). TEF and EA are two components of VACTERL association of congenital anomalies: "V" for vertebral or vascular anomalies, "A" for anal atresia, "C" for cardiac abnormalities, " $T$ " for tracheoesophageal fistula, "E" for esophageal atresia, "R" for renal abnormalities, and "L" for limb anomalies., ${ }^{2,3}$ VACTERL is an association rather than a syndrome as its components are not pathologically caused but embryologically formed due to mesodermal defects. ${ }^{4}$ When at least two ${ }^{5}$ or three ${ }^{6,7}$ components of these congenital anomalies are identified in the same neonate, VACTERL association is diagnosed. Patients with EA most likely suffer from gastroesophageal reflux disease (GERD). ${ }^{8}$

Children with EA/TEF have a greater incidence of laryngeal cleft than other free children. ${ }^{9}$ Neonatal surgical repair of ET/TEF is usually lacks sufficient preoperative information about the anatomy of these structures. ${ }^{10}$ Postoperative complications of EA/TEF surgical repair include recurrence, intestinal sequestration, and repeated thoracic drainage procedures. ${ }^{11}$

A rare congenital esophageal diverticulum in children is commonly non-symptomatizing; it may be complicated with a bronchoesophageal fistula leading to chronic cough due to recurrent pneumonia. Anterolateral thoracotomy is adopted to excise the diverticulum and close the fistula. ${ }^{12}$ In an adult woman, a rare congenital bronchoesophageal fistula with intralobar pulmonary sequestration was thoracoscopically excised with favoring results. ${ }^{13}$

\section{Congenital umbilical fistulas}

Congenital umbilical anomalies result from persistent patency of the vitellointestinal duct (VID), the allantois (urachus) or the umbilical ring. Congenital umbilical fistulas (CUFs) result from failure of obliteration of either of the VID or the urachus. They are identified postnatally when signs of umbilical pathology: swelling, redness, or discharge are observed. ${ }^{14}$ Meckel's diverticulum is the commonest congenital anomaly of the gastrointestinal tract; it occurs in $1-3 \%$ of autoptic specimens. ${ }^{15}$ In early development, the fetal VID (omphalomesenteric duct: OMD) connects the midgut loop with the yolk sac; with further development it is obliterated and degenerated leaving no remnants. Partial or complete patency of VID results in Meckel's diverticulum, vitelline cyst or vitellointestinal fistula; the latter is associated with persistent fecal umbilical discharge dated since birth. ${ }^{16-19}$ A patent OMD is commonly connected to the ileum but rarely to the caecum or vermiform appendix. ${ }^{20} \mathrm{Few}$ cases of rare neonatal congenital umbilical vermiform appendices with appendico-umbilical fistulas are reported. VID fistulas may be also iatrogenic in etiology due to faulty clamping and severing of umbilical cords containing herniated midgut loops..$^{21,22}$ Few cases of rare congenital fistulation of Meckel's diverticulum to the surface of an intact exomphalos sac are reported. ${ }^{23,24}$ A case of a child discharging a roundworm through the umbilicus was described as a strange presentation of a patent VID. ${ }^{25}$ 
Another case of a congenital umbilical fistula discharging bile was also discovered in a full-term neonate; it communicated with the intrahepatic biliary system. ${ }^{26}$ Closure of the congenital umbilical intestinal fistulas in children is recommended as persistence of fistula results in the formation of intraabdominal adhesions. ${ }^{27}$

The allantois (allanto-enteric diverticulum) is an endodermal diverticulum extending from the ventral part of the cloaca (termed the primitive urogenital sinus) toward the umbilical ring. The cloaca is the dilated caudal end of the hindgut. With further development, the allantois becomes narrowed and termed the urachus of which the proximal part forms the apex of the urinary bladder whereas the distal part becomes obliterated and persists as the median umbilical ligament. ${ }^{28}$ Congenital urachal anomalies: cysts, fistulas, sinuses, and diverticula are very rare. ${ }^{29}$ Urachal abnormalities result from either incomplete fetal obliteration of the urachus or postnatal regression leading to recanalization of the urachus after its closure. ${ }^{30}$ Fistulography and ultrasonography are valuable diagnostic methods and complete urachal excision is the treatment of choice. ${ }^{31,32}$ Congenital patent urachus in adults is rarely reported; in a middle-aged Japanese male a urachal fistula was resected together with partial cystectomy. ${ }^{33}$ It is advisable not to excise the umbilicus in such cases, and laparoscopic surgery seems to be of satisfactory outcome. ${ }^{34}$

A congenital prepubic sinus (CPS) is another rare abnormality that is supposed to be due to persistence of a part of the cloacal membrane. ${ }^{35}$ A case of midline CPS was described to extend from the prepubic skin to the superior surface of the urinary bladder, then to the umbilicus along the median umbilical ligament. ${ }^{36}$ In a boy suffering from abnormal dribbling of urine from his perineum, a congenital posterior urethroperineal fistula was extending from the posterior urethra to the perineal skin. ${ }^{37}$ However, a urethrocutaneous ventral fistula of the penis might be iatrogenic due to traumatic injury during a previous circumcision. ${ }^{38}$ Anterior perineal sinuses along the median raphe are supposed to be due to congenital midline inclusion disorders ${ }^{39}$ whereas pilonidal sinus and pyoderma fistulans sinifica are considered as retention skin lesions and not of congenital origin. ${ }^{40}$

\section{Congenital vascular fistulas}

Congenital coronary artery fistulas are abnormal communications between the coronary arteries and the four cardiac chambers or the great vessels of the heart. Rare coronary arteriovenous fistulas are often congenital but may be iatrogenic. ${ }^{41,42}$ Microfistulas were detected between the left anterior descending artery and the left ventricular cavity on cardiac catheterization of an old patient. ${ }^{43}$ Rare origin of the left main coronary artery from the right Valsalva sinus is a congenital anomaly that is commonly associated with coronary fistulas and other cardiac abnormalities; such coronary anomaly is described in the literature as a rare association with Marfan syndrome. ${ }^{44}$ An uncommon combination of congenital coronary anomalies (atresia, stenosis and fistula) in a child was diagnosed and surgically managed. ${ }^{45}$

Ductus venosus is a normal fetal shunt between the left branch of the portal vein and the inferior vena cava (IVC). It is obliterated at birth to form the ligamentum venosum of the liver. Rare absence of the ductus venosus may be seriously associated with abnormal umbilical vein that bypasses the liver (and IVC) and directly terminates into the right atrium. ${ }^{46}$

Congenital arteriovenous fistula (AVF) is extremely rare. An AVF is reported between the left internal thoracic (mammary) artery and the ductus venosus. ${ }^{47}$ A rare neonatal congenital AVF between the inferior epigastric arteries and the umbilical vein had resulted in a clinical condition simulating congestive heart failure; the affected vessels were surgically ligated and excised..$^{48}$ A rare congenital systemic-pulmonary AVF, manifested by pulmonary hypertension, was detected on using aortic angiography and echocardiography. ${ }^{49}$ An extremely rare case of congenital intrahepatic AVF was prenatally diagnosed. ${ }^{50} \mathrm{~A}$ fistula between the internal thoracic artery and the pulmonary vessels is a rare congenital anomaly, it could be also iatrogenic in case of coronary artery surgery, trauma or neoplasms. ${ }^{51}$ A congenital pulmonary AVF is mentioned to be a risk factor for embolic stroke. ${ }^{52}$ An extremely rare congenital fistula between the right pulmonary artery and the left atrium may cause cardiac failure in utero. ${ }^{53}$ Congenital aortocaval fistula between the right sinus of Valsalva and the superior vena cava is a very rare anomaly that causes left to right shunt. ${ }^{54}$ In the rare congenital aorto-atrial fistulas, abnormal connections exist between the different parts of aorta and the atria leading to volume overload and heart failure. ${ }^{55} \mathrm{AVF}$ between the inferior mesenteric artery and vein is very rare and it may cause ischemic colitis. ${ }^{56}$ An extremely rare case of an ilio-iliac AVF is also reported in the literature with atypical clinical manifestations. ${ }^{57}$

\section{Congenital fistulas in the nervous system}

Arteriovenous fistulas are rarely encountered in the nervous system. A congenital cranial pial AVF is extremely rare. A pial AVF was detected originating from the left middle cerebral artery and terminating into the superior sagittal venous sinus. ${ }^{58}$ Also, there is a report of a prenatally diagnosed intracranial pial AVF ending into the great cerebral vein of Galen; it was treated in the early neonatal life. ${ }^{59}$

Spinal cord arteriovenous fistulas may exist in the spinal cord itself or in the spinal meninges. They include the spinal dural AVF as the commonest and acquired lesion and the spinal pial AVF as the less common and congenital lesion. The co-existence of different types of spinal cord arteriovenous shunts is very rare. ${ }^{60}$ Concomitant existence of spinal lipoma and acquired spinal AVF is also very rare. The lipoma releases angiogenic factors that are involved in the development of the spinal AVF. ${ }^{61}$

\section{Conclusion}

An adequate knowledge of the pathoembryology of the congenital diverticula, cysts, sinuses and fistulas, at different body regions, is essential for proper prenatal and early postnatal diagnosis. Early intervention in such cases is necessary for minimizing postoperative complications.

\section{Acknowledgements}

None.

\section{Conflict of interest}

The author declares no conflict of interest.

\section{References}

1. Heshmat SWH. Congenital craniofacial and cervical cysts, sinuses and fistulas - A review article. Sch J Oto. 2018;1(1):18-101.

2. Ognean ML, Zgârcea LC, Bălănescu L, et al. Esophageal atresia with distal fistula - unusual case series. Considerations related to epidemiological aspects, malformative associations, and prenatal diagnosis. Rom J Morphol Embryol. 2017;58(3):1069-1076.

3. de Jong EM, Felix JF, Deurloo JA, et al. Non-VACTERL-type anomalies 
are frequent in patients with esophageal atresia/tracheo-esophageal fistula and full or partial VACTERL association. Birth Defects Res A Clin Mol Teratol. 2008;82(2):92-97.

4. Padma S, Sundaram PS, Sonik B. A case of VACTERL and non-VACTERL association without the "V and L". Indian J Nucl Med. 2014;29(1):46-49.

5. Rittler M, Paz JE, Castilla EE. VACTERL association, epidemiologic definition and delineation. Am J Med Genet. 1996;63(4):529-536.

6. Puvabanditsin S, Van Gurp J, February $M$, et al. VATER/VACTERL association and caudal regression with Xq25-q27.3 microdeletion: a case report. Fetal Pediatr Pathol. 2016;35(2):133-141.

7. Peonim V, Sujirachato K, Udnoon J, et al. Aberrant abdominal umbilical arteries in VACTERL--association: a first case report. $J$ Med Assoc Thai. 2012;95(10):1352-1356.

8. Mousa H, Krishnan U, Hassan M, et al. How to care for patients with EA-TEF: the known and the unknown. Curr Gastroenterol Rep. 2017;19(12):65

9. Londahl M, Irace AL, Kawai K, et al. Prevalence of laryngeal cleft in pediatric patients with esophageal atresia. JAMA Otolaryngol Head Neck Surg. 2018;144(2):164-168.

10. Higano NS, Bates AJ, Tkach JA, et al. Pre- and post-operative visualization of neonatal esophageal atresia/tracheoesophageal fistula via magnetic resonance imaging. J Pediatr Surg Case Rep. 2018;29:5-8.

11. Dylkowski D, Dave S, Andrew McClure J, et al. Repair of congenital esophageal atresia with tracheoesophageal fistula repair in Ontario over the last 20 years: Volume and outcomes. J Pediatr Surg. 2018;53(5):925-928.

12. Wang ZM, Zhang SC, Teng X. Esophageal diverticulum serves as a unique cause of bronchoesophageal fistula in children: A case report. Medicine (Baltimore). 2017;96(51):e9492.

13. Sakanoue I, Hamakawa H, Imai Y, et al. Thoracoscopic surgery for congenital bronchoesophageal fistula with pulmonary sequestration in an adult woman. Semin Thorac Cardiovasc Surg. 2017;29(3):433-435.

14. Alessandrini P, Derlon S. Congenital umbilical fistulas. A report of 12 cases. Pediatrie. 1992;47(1):67-71.

15. Natta F, Passarelli E, Rosso MV. Meckel's diverticulum. Personal experience. Minerva Chir. 1994;49(6):529-532.

16. Walji-Virani S, Russo MA. An infant with yellow umbilical drainage. Diagnosis: Patent omphalomesenteric fistula. Gastroenterology. 2011;140(7):e5-e6.

17. Ali A, Jawale AR, Cama J. Vitello-intestinal duct fistula--a rare presentation of a patent vitello-intestinal duct: a case report. Pac Health Dialog. 2010;16(2):67-69.

18. Dansen MJ, Baartmans MG. Diagnostic image (343). A neonate with a red swollen umbilicus. Ned Tijdschr Geneeskd. 2007;151(39):2147.

19. Chattopadhyay A, Mukhopadhyay B, Tripathy BB. Spontaneous fecal fistula in a neonate. Indian J Pediatr. 2009;76(3):317-318.

20. Crankson SJ, Ahmed GS, Palkar V. Patent omphalomesenteric duct of the vermiform appendix in a neonate: congenital appendicoumbilical fistula Pediatr Surg Int. 1998;14(3):229-230.

21. Fuijkschot J, Wijnen RM, Gerrits GP, et al. A neonate with an intact congenital umbilical appendix: an alternative theory on the etiology of the appendico-umbilical fistula. Pediatr Surg Int. 2006;22(8):689-693.

22. Jona JZ. Congenital hernia of the cord and associated paten omphalomesenteric duct: a frequent neonatal problem? Am J Perinatol. 1966;13(4):223-226.

23. Mavridis G, Livaditi E, Vassiliadou E, et al. Intrauterine fistulation of perforated Meckel's diverticulum to the surface of the sac of an intact exomphalos minor. Minerva Pediatr. 2008;60(2):253-254.

24. Hale PC, Agrawal M. Congenital fistulation of a Meckel's diverticulum to the surface of an exomphalos sac. Br J Clin Pract. 1993;47(5):273.

25. Perera J. Patent vitello-intestinal duct: an unusual presentation. Ceylon Med J. 1993;38(3):140-142.

26. Mohta A, Upreti L, Jagdish S. Umbilicobiliary fistula in a neonate. Pediatr Radiol. 2006;36(5):432-433.

27. Misharev OS, Zakrevskiǐ GI. Congenital intestinal fistulae of the umbilicus in children. Vestn Khir Im I I Grek. 1981;127(7):89-91.

28. Sadler TW, Thomas W, Langman J. Langman's medical embryology. 11th ed. Philadelphia, USA: Wolters Kluwer, Lippincott Williams \& Wilkins; 2010:400.

29. Nielsen TP, Nelson RM, Lee-Green B, et al. Patent urachus complicating pregnancy: a review and report of a case. Am J Obstet Gynecol. 1982;143(1):61-68.

30. Gómez Barbadillo J, Plata Rosales J, Espinosa Guzmán E, et al. Urachalsigmoid fistula in an adult male without urachal cyst. Rev Esp Enferm Dig. 2002;94(7):430-434

31. Descazeaud A. Urachal diseases. Ann Urol (Paris). 2007;41(5):209-215.

32. Takano M, Yamashita S, Inuzuka S, et al. Patent vitelline duct in an adult deceptively appeared to be acquired umbilical urachal sinus: a case report. Hinyokika Kiyo. 1995;41(8):613-616.

33. Takano Y, Okatani K, Okamoto S, et al. Congenital patent urachus in an adult: a case report. Int J Urol. 1994;1(3):275-277.

34. Renard O, Robert G, Guillot P, et al. Benign urachus abnormalities: embryology, diagnosis and treatments. Prog Urol. 2008;18(10):634-641.

35. Tsukamoto K, Yamataka A, Kuga T, et al. Congenital prepubic sinus: is it a residual cloacal membrane and umbilicophallic groove? Pediatr Surg Int. 2004;20(1):47-50.

36. Park WH, Choi SO, Park KK, et al. Prepubic dermoid sinus: possible variant of dorsal urethral duplication (Stephens type 3). J Pediatr Surg. $1993 ; 28(12): 1610-1611$.

37. Perez JF, Díaz B AM, Ramos GU, et al. Congenital posterior urethral fistulae: literature review and case report. Urol Int. 2018;101(1):121-124.

38. Moradi M, Kaseb K, Rezaee H. Giant urethrocutaneous fistula following ritual circumcision in an infant with congenital anterior urethral diverticula. SAGE Open Med Case Rep. 2017;5:2050313X17745205.

39. Oliver GC, Rubin RJ, Salvati EP, et al. Anterior perineal sinus. Dis Colon Rectum. 1991;34(9):777-779.

40. Stelzner F. Causes of pilonidal sinus and pyoderma fistulans sinifica. Langenbecks Arch Chir. 1984;362(2):105-118.

41. Chae U, Lee MY, Kim H, et al. Prenatal diagnosis of isolated coronary arteriovenous fistula. Obstet Gynecol Sci. 2018;61(1):161-164.

42. Yamauchi T, Gon S, Saito M, et al. Coronary arteriovenous fistula in continuity with the aortic arch. Ann Thorac Surg. 2018;105(5):e195-e197.

43. Qureshi R, Kao L, Gupta RP. Coronary artery fistula with associated Takotsubo cardiomyopathy: a case report. J Med Case Rep. 2018;12(1):86.

44. Duarte SBCP, Beraldo DO, Cesar LAM, et al. Anomalous coronary artery origin in a young patient with marfan syndrome. Case Rep Cardiol. $2017: 3861923$

45. Pandya NR, Venugopal P, Wildschut J, et al. Three's a crowd-a unique combination of coronary artery atresia, fistula, and stenosis: multiple congenital coronary artery anomalies. World J Pediatr Congenit Heart Surg. 2018;1:2150135118757990. 
46. Sothinathan U, Pollina E, Huggon I, et al. Absence of the ductus venosus. Acta Paediatr. 2006;95(5):620-621.

47. Stanford W, Fixler DE, Armstrong RG, et al. Congenital arteriovenous fistula between the left internal mammary artery and the ductus venosus. A case report. J Thorac Cardiovasc Surg. 1970;60(2):248-252.

48. Hager J, Gschnitzer F, Hammerer I, et al. Congenital epigastric-umbilica arteriovenous fistula. Contribution on a rare clinical picture. Langenbecks Arch Chir. 1982;357(4):269-273.

49. Shi YP, Li YD, Lv XZ, et al. Systemic-pulmonary arteriovenous fistulae with pulmonary hypertension: a case report. Medicine (Baltimore). 2018;97(8):e9959.

50. Douhnai D, Tassin M, Sibiude J, et al. Prenatal diagnosis of intra hepatic arteriovenous fistula: case report and review of the literature. $J$ Matern Fetal Neonatal Med. 2018;20:1-4.

51. Abdul Jabbar A, Patel A, Marzlin N, et al. Internal mammary artery-topulmonary vasculature fistula: Systematic review of case reports. Vasc Med. 2017;22(5):426-431.

52. Sousa S, Vasco Costa N, Carmona C, et al. Recurrent stroke in a young woman with a single pulmonary arteriovenous fistula: An unusual association. Case Rep Neurol. 2017;9(3):293-298.

53. Yakut K, Varan B, Ozkan M. A rare cause of cyanosis in newborns: arteriovenous fistula between the right pulmonary artery and the left atrium and its treatment. Cardiol Young. 2018;28(4):605-607.
54. Dabirian M, Ghaemian A, Nabati M, et al. Congenital aortocaval fistula between right aortic sinus of Valsalva and superior vena cava: A rare case report. Echocardiography. 2018;35(3):413-416.

55. Fierro EA, Sikachi RR, Agrawal A, et al. Aorto-atrial fistulas: a contemporary review. Cardiol Rev. 2018;26(3):137-144.

56. Lee S, Chung J, Ahn B, et al. Inferior mesenteric arteriovenous fistula. Ann Surg Treat Res. 2017;93(4):225-228.

57. Coelho A, Brandão P, Lobo M, et al. Ilio-iliac arteriovenous fistulae-an unusual diagnosis with an even more unusual clinical presentation. Ann Vasc Surg. 2018;50:298.e1-298.e5.

58. Xin SB, Wang GB, Liu WJ, et al. Congenital intracerebral pial arteriovenous fistula: a case report. J Neurol Surg A Cent Eur Neurosurg. 2018;79(2):173-176.

59. Köroğlu M, Cil B, Yeşildağ A, et al. Prenatal diagnosis of intracranial pial arteriovenous fistula and endovascular treatment during the neonatal period. Diagn Interv Radiol. 2006;12(2):64-67.

60. Rosi A, Consoli A, Condette-Auliac S, et al. Concomitant conus medullaris arteriovenous shunts and sacral dural arteriovenous fistulas: pathophysiological links related to the venous drainage of the lesions in a series of five cases. J Neurointerv Surg. 2018;10(6):586-592.

61. Horiuchi Y, Iwanami A, Akiyama T, et al. Spinal arteriovenous fistula coexisting within a spinal lipoma: report of two cases. Spinal Cord Ser Cases. 2017;3:17079. 